\title{
ANÁLISIS ESTÉTICO DENTOFACIAL: BASE DE LA TERAPÉUTICA EN DEFORMIDADES FACIALES
}

\section{DENTOFACIAL AESTHETIC ANALYSIS: BASIS OF THERAPEUTICS IN FACIAL DEFORMITIES}

\author{
Cazar Almache Marcelo, ${ }^{1 *}$ Abril Cordero Marina, ${ }^{2}$ Recendez Santillán Norith de Jesús ${ }^{3}$ \\ ${ }^{1}$ Cirujano Maxilofacial Profesor Titular de Cirugía Oral y Maxilo Facial de la Universidad de Cuenca. Ecuador. \\ 2 Radióloga Bucomaxilofacial, Docente de la Universidad de Cuenca. Ecuador. \\ ${ }^{3}$ Cirujano Maxilofacial Monterrey México.México. \\ *marcelo.cazar@ucuenca.edu.ec
}

\begin{abstract}
Resumen
Resumen: El análisis y diagnóstico de las alteraciones dento faciales, constituye la base del tratamiento ortodóntico quirúrgico de las deformidades del macizo facial desde un abordaje funcional para llegar a lo estético mediante herramientas clínicas y tecnológicas como son estudios de imagen: cefalometria, tomografías haz de cono y modelos estereolitograficos. El estudio de la estética facial del ser humano ha sido desarrollado desde la antigüedad en base de los canones clásicos, que han marcado como norma en el subconsciente colectivo a los patrones griegos como la norma estándar de belleza facial y que no siempre coinciden con todos los grupos étnicos como es el caso de la sociedad ecuatoriana. El presente trabajo pretende dar al estudiante de pre y pos grado de nuestro medio una metodología para abordar la complejidad del análisis estético dento facial acoplando la interpretación clásica a nuestra multiculturalidad.
\end{abstract}

Palabras clave: Deformidades Dentofaciales, Estética.

\begin{abstract}
Summary: The analysis and diagnosis of dentofacial alterations is the basis of the surgical orthodontic treatment of facial skull mass, facial deformities from a functional approach to aesthetics through clinical and technological tools such as imaging studies: cephalometric, cone beam tomography and stereolithographic models. The study of the facial aesthetics of the human being has been developed since antiquity based on the classic canons, which have marked as standard in the collective subconscious, the greek standards as the standard norm of facial beauty and that do not always coincide with all ethnic groups as in the case of Ecuadorian society. The present work intends to give to the student of pre and post of our means a methodology to approach the complexity of the aesthetic analysis dento facial coupling the classic interpretation to our multiculturalism.
\end{abstract}

Key words: Dentofacial Deformities,Esthetics.

\section{INTRODUCCIÓN}

Desde tiempos remotos la estética facial representa en la sociedad un punto clave en el desarrollo del ser humano, relacionada con la simetría y la armonía espacial de diversas estructuras que en conjunto manifiestan una apariencia agradable; siendo así, la belleza es definida como una apreciación subjetiva resultante de la combinación de proporciones armoniosas y cualidades que en conjunto se perciben como algo agradable para los sentidos. La belleza se ha establecido desde hace varios siglos; un ejemplo de ello es representado durante la época del renacimiento, por el científico y artista Leonardo da Vinci, quien hizo hincapié en la importancia de la armonía entre el arte y la ciencia, definiendo a la belleza de acuerdo a la proporción y la relación de las respectivas partes que forman un todo, plasmado en la figura del hombre de Vitruvio (1490), ${ }^{1}$ basado en las directrices de simetría descritas por el arquitecto romano Marcos Vitruvius, mostrando la importancia de las proporciones en la forma humana. El mismo inicia las descripciones de simetría facial mostrando las proporciones de la cabeza humana en relación del cuerpo, citando que la distancia de la parte superior de la cabeza al mentón deberá representar un octavo de la altura total del cuerpo del individuo. ${ }^{2}$ 


\subsection{ESTADO DEL ARTE.}

Actualmente existen diversos parámetros en el análisis dentofacial del paciente tales como la raza, edad, sexo que deben ser considerados para la opción terapéutica más indicada de acuerdo a la individualidad del mismo y su desempeño en sociedad. El tratamiento para un paciente con deformidad dentofacial representa diversas consideraciones estéticas propias para el paciente, siendo contemplado desde el inicio en el interrogatorio al mismo de las necesidades en el cambio estético y funcional individual. La habilidad clínica de modificar las formas dentofaciales a través de ortodoncia, ortopedia maxilo mandibular, o mediante cirugía requiere un entendimiento absoluto de los cánones de belleza y una observación detallada de las proporciones y simetrías faciales individuales de cada paciente. Actualmente se considera que el tratamiento ortodóntico-quirúrgico encaminado a Cirugía Ortognática deberá considerar su análisis facial de los tejidos blandos en posición estática y dinámica, características particulares y armónicas en el paciente, individualidad del mismo en patrones estéticos de acuerdo a raza y sexo, posición de estructuras óseas y funcionalidad del aparato estomatognatico, obteniendo en la suma de dichos puntos el alcanzar un adecuado balance para el complejo dentofacial. De especial importancia debemos incluir en este concepto la evaluación de modelos de estudio y análisis cefalométricos los cuales en conjunto nos guiarán en el alcance de un tratamiento quirúrgico adecuado y no basándose en el cefalograma lateral únicamente debido a que valora al paciente en medidas esqueletales sin considerar la interrelación de las partes craneofaciales desde el punto de vista multidireccional. La funcionalidad en estándares cefalomètricos, no siempre conlleva un resultado estético favorable, o viceversa. Considerando el análisis de arcadas mediante modelos únicamente valoran el futuro funcional de intercuspidaciòn del paciente y no proporcionan información concerniente al aspecto facial final de éste. ${ }^{3}$ La valoración facial y cefalomètrica de tejidos blandos para la planificación de tratamiento es descrita por Arnett y cols, ${ }^{4}$ mediante siete pasos los cuales incluyen el análisis dimensional anteroposterior y vertical, mediante la evaluación de la vista frontal facial, líneas medias dentales en relación con línea media facial, posición de labios y exposición dental durante la sonrisa, contorno facial, perfil facial con evaluación de proyección anteroposterior de tercio medio e inferior; que en conjunto conlleva la decisión de los movimientos quirúrgicos y cirugía de modelos en el articulador.(Figura 1) El análisis facial mediante el recurso fotográfico permite evaluar al paciente de la mejor manera cuando buscamos la posición natural de la cabeza, posición de relación céntrica, contacto dentario inicial y labios relajados en cada una de las proyecciones faciales.(Figura 2)

Las imágenes frontales en reposo, frontal de sonrisa y laterales son consideradas como básicas para la realización de este análisis. Se consideran anexas a la evaluación de las mismas y por lo mucho importantes, las fotografías tres cuartos y céfalo-caudal para el análisis integral del paciente, inclusive se recomienda realizar captura de video imágenes que apoyaran al clínico para el registro dinámico y mejorar el análisis de la expresión facial en el paciente. ${ }^{5}$

Dicho análisis será entonces desde tres puntos de vista importantes: análisis facial de tejidos blandos, análisis de sonrisa y análisis intraoral de las arcadas dentales. ${ }^{6}$

\section{La evaluación extraoral frontal deberá incluir:}

1) Evaluación de altura facial.

2) Balance de tercios faciales.

3) Ancho facial.

4) Espacio interlabial.

5) Exposición de incisivos centrales inferiores y superiores.

6) Exposición de encía durante la sonrisa Área paranasal.

7) Largo y ancho nasal.

8) Posición de bermellón labial.

9) Asimetrías mandibulares y de mentón.

\section{Evaluación de perfil facial y tres cuartos.}

1) Tipo de perfil.

2) Proyección anteroposterior maxilar.

3) Proyección anteroposterior mandibular y de mentón.

4) Distancia interlabial.

5) Proyección de bermellón labial.

6) Proyección de punta nasal

7) Evaluación paranasal y proyección de reborde orbitario inferior.

8) Área submentoniana y cervical.

Examinación intraoral de arcada mandibular y maxilar.

1) Forma y tamaño.

2) Apiñamiento dental.

3) Posición de incisivos.

4) Línea media dental.

5) Tamaño de corona clínica.

6) Morfología de encía, cantidad de encía insertada.

7) Sonrisa: simetría, diámetro transverso.

\subsection{ANÁLISIS FRONTAL}

Resulta importante el análisis frontal, debido a que es la manera en que cotidianamente se percibe a sí mismo el paciente, se analiza de manera de sus dimensiones verticales y transversales. Se tomarán en cuenta diversos puntos anatómicos para el análisis estético, dentro de los cuales los ubicamos de la siguiente forma:

1) Triquion (línea de implantación del cabello).

2) Glabela (porción más promienente de región interciliar).

3) Canto palpebral externo.

4) Canto palpebral interno.

5) Zigion (porción más lateral del arco cigomático, de acuerdo al contorno facial).

6) Subnasal.

7) Base nasal.

8) Comisura labial. 


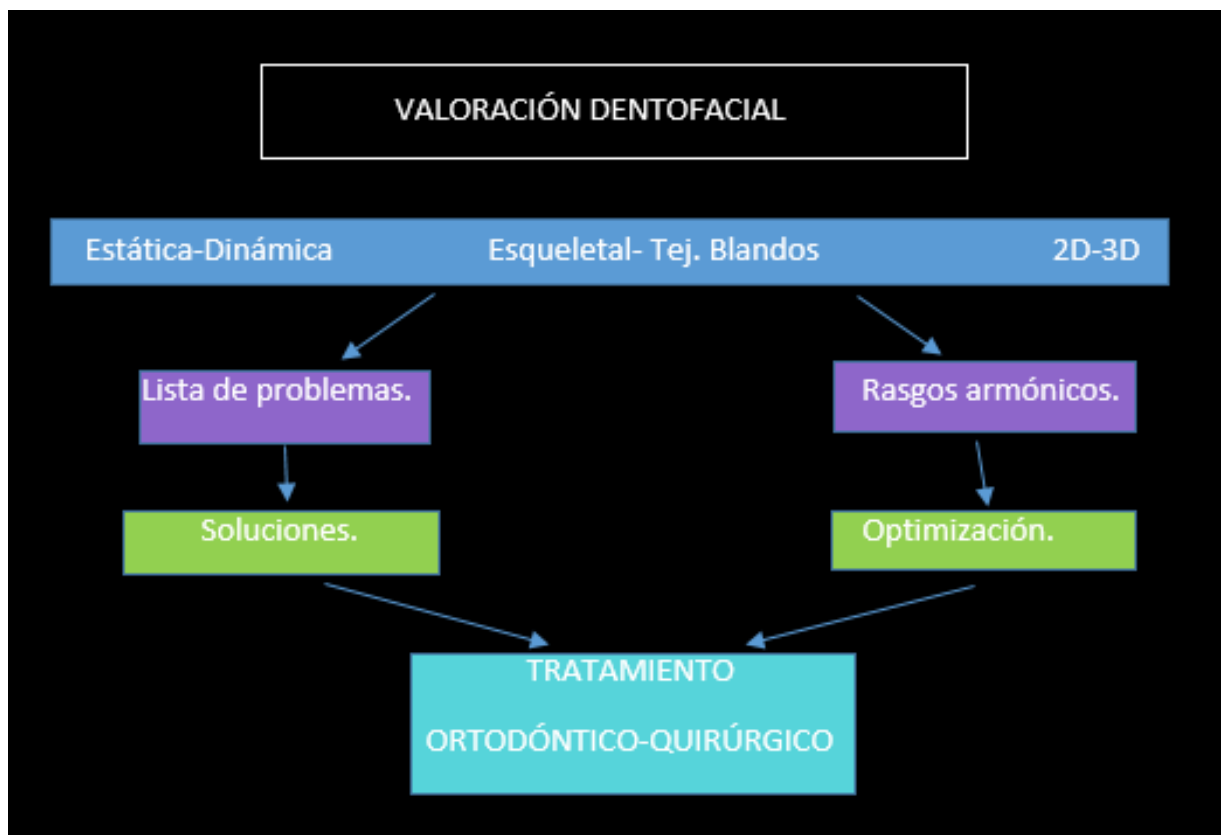

Fig. 1. Flujograma de objetivos para valoración en pacientes con deformidades dentofaciales.

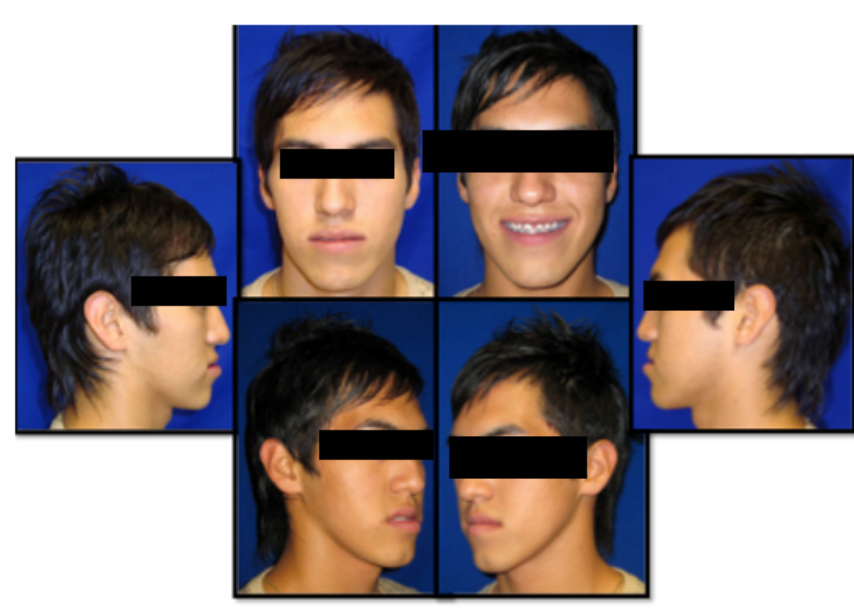

Fig. 2. Serie de fotografías para análisis estético facial.

9) Gonión(ángulo de la mandibula).

10) Gnation (límite más inferior del contorno facial en la sínfisis mentoniana).(Figura 3)

Es necesario observar las relaciones que existen entre la altura y el ancho facial(Figura 4) lo que nos determinara el tipo facial al que nos estamos enfrentando, siendo determinado por el análisis de los tercios y quintos faciales. Obteniendo así tres biotipos faciales: dolicofacial, (cuando el tercio inferior se encuentra alargado, dando una apariencia de "cara larga"), braquifacial regularmente cuando el tercio inferior se encuentra acortado y el paciente presenta una anchura facial fuera de la norma, "cara cuadrada"), y meso facial, (apariencia armónica entre los tercios faciales). A esto determinamos como formas faciales obteniendo dicho análisis mediante el trazado de una línea vertical que vaya del triquion al mentón de tejidos blandos y dos líneas perpendiculares a esta, a la altura de los puntos cigomáticos (parte más prominente del cuerpo del cigoma) y la segunda línea uniendo el punto Gonión de manera bilateral. Contando con una norma de altura-anchura facial en hombres de 1.35:1 y de 1.3:1 en mujeres, siendo en un $30 \%$ menor la anchura facial en relación a su altura. ${ }^{7}$

El análisis vertical facial, de los tercios faciales consiste en dividir el rosto con una línea horizontal en relación a la línea de implantación del cabello, el punto glabela de tejidos blandos la base nasal y el límite inferior del mentón. Teniendo una norma de 1/3 para cada segmento facial. A su vez el tercio inferior puede ser dividido a través de las comisuras labiales, en donde se observa que la mayor altura está representada por la distancia vertical del labio inferior siendo la norma establecida de $48 \mathrm{~mm}$ en mujeres y $53 \mathrm{~mm}$ en hombres y la altura promedio del labio superior varía entre los $20-22 \mathrm{~mm} .{ }^{8}$ no olvidando tomar en cuenta la exposición dental interlabial que oscila entre 1- $5 \mathrm{~mm}$ la cual brinda una armonía facial agradable, en el caso contrario resulta indicativo analizar la posibilidad de crecimiento excesivo vertical del maxilar, o bien sospechar de un una altura labial superior corta, así como nos facilitaría observar si existe alguna discrepancia vertical en la región mentoniana. Concluyendo que la proporción normal entre la relación del labio superior y el inferior / mentón 


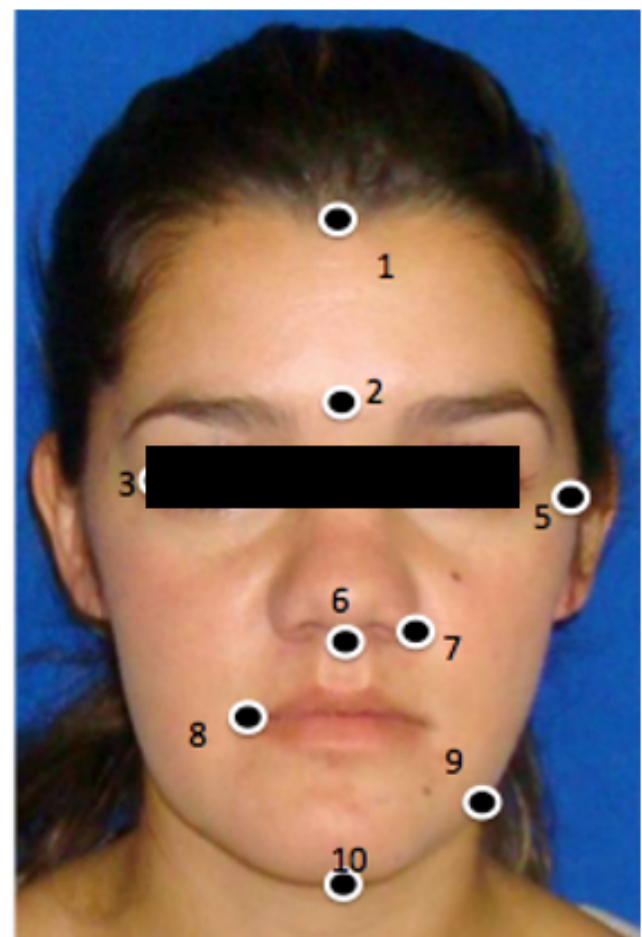

Fig. 3. Puntos cefalométricos en tejidos blandos.

deberá ser de 1:2 respectivamente. Siendo en porcentaje de altura facial total ocupado por el $30 \%$ labio superior y de labio inferior- mentón un $70 \% .{ }^{9}$ (Figura 5)

El análisis facial transverso consiste en la división de la cara en 5 partes (regla de los quintos) divididas por líneas verticales que transectan sagitalmente la cara en:

1) La parte más externa del hélix hasta el contralateral, denominándose como porción media facial.

2) Línea que transecte el canto externo palpebral y coincida con la comisura bucal.

3) Construcción de una línea vertical que atraviese la comisura palpebral interna y la base nasal. ${ }^{10}$

Una línea adicional al análisis de los quintos se traza en relación del límite medial de la pupila la cual deberá coincidir con la comisura bucal, siendo excluida en su corrección cuando se planea una cirugía maxilomandibular. ${ }^{6}$ Éste análisis aplicado en el paciente de la (Figura 6) nos permitiría observar que la prominencia mandi

bular se debe a la región de sus ángulos (hipertrofia maseterina) la cual podría ser corregida únicamente con uso de toxina botulínica para tratamiento de mismo padecimiento, lo que obviaría una intervención quirúrgica inapropiada, siendo esta una de las tantas aplicaciones de la correcta observación del paciente. La simetría facial derecha e izquierda deberá analizarse trazando una línea sagital al rostro del paciente, pasando por los puntos: glabela, dorso nasal, punta nasal,

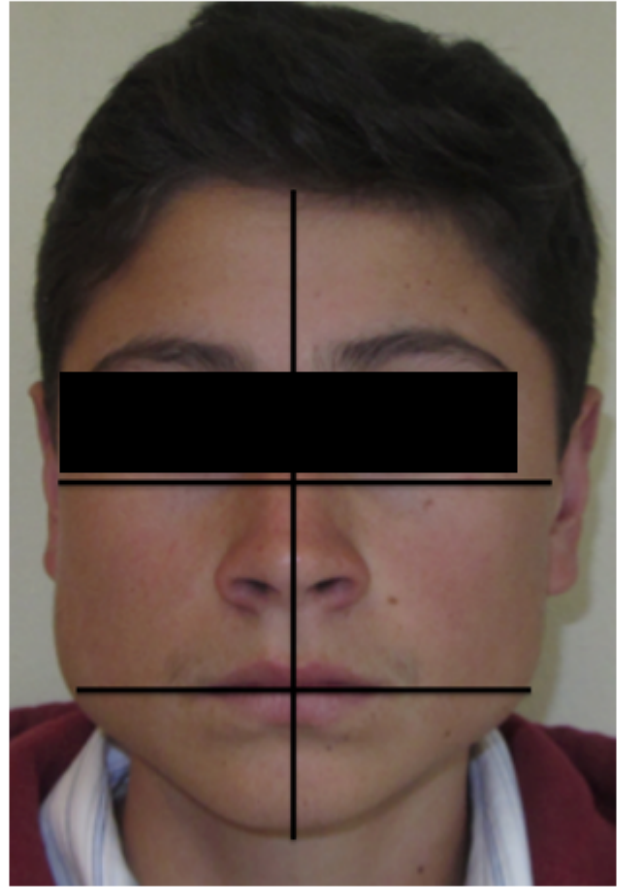

Fig. 4. Se observa paciente con hiperplasia maseterina en la que la distancia bigonial e igual a la anchura intercigomàtica saliendo de la norma estética.

parte media del filtrum, línea media dental, porción media de sínfisis mentoniana. ${ }^{6}$ Teniendo en consideración relacionar la línea media dental maxilar y mandibular en relación a la línea sagital facial, discrepancia en tercios faciales como análisis de dorso nasal, desviación de sínfisis mentoniana, lo que nos marcará la pauta para realizar una corrección quirúrgica mandibular o bien una genioplastia para corregir un mentón desalineado; o bien relacionando a las líneas medias dentales y la facial podríamos descartar algún problema en relación posicional dental en la arcada maxilar que requiera corrección ortodóntica o bien un problema esqueletal.(Figura 7)

Se tiene que correlacionar la evaluación clínica (Figura 8) con las herramientas digitales (Figura 9) que se encuentran a nuestro alcance volviéndose imprescindible la aplicación del objetivo visual al inicio, durante y final del tratamiento

\subsection{OBJETIVO VISUAL DEL TRATAMIENTO (VTO)}

Determina la contribución del crecimiento al corregir la mala oclusión a través de los movimientos planificados. Permite visualizar las modificaciones que sufrirán las estructuras dento esqueléticas con el crecimiento y la parte del tratamiento mecánico a realizar anticipando la estética de los tejidos blandos a obtener. Se realiza la evaluación de siete áreas y la superposición de cinco áreas. Permitiendo visualizar los cambios a nivel de maxilares, piezas dentarias 


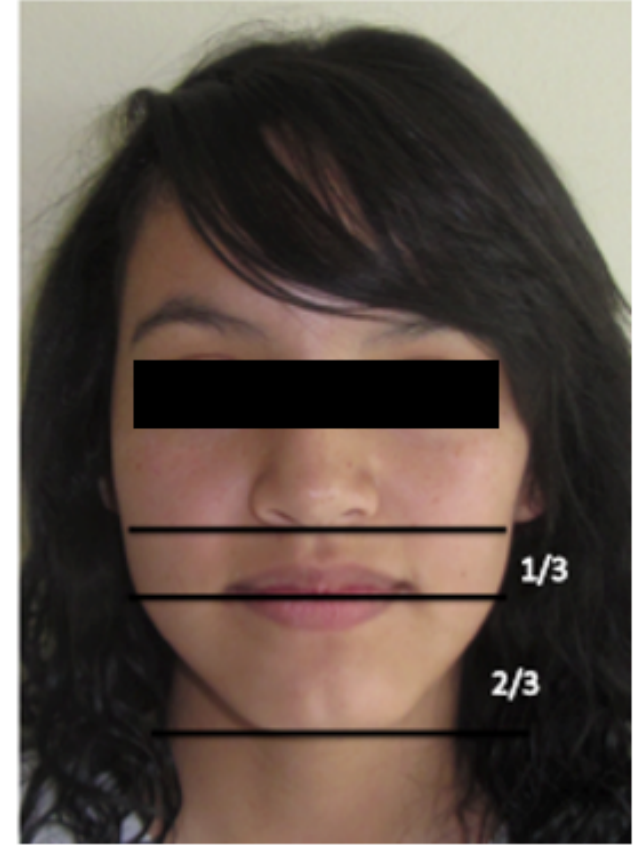

Fig. 5. Proporción vertical de tercio inferior.

$\mathrm{y}$ tejidos blandos que se producen por crecimiento normal o tratamiento realizado. En la superposición obtenemos información según el estado o etapa de tratamiento ya que se puede obtener información del estado actual al realizar el trazado inicial o el avance de tratamiento. De la misma manera, al realizar el trazado inicial y final para valorar el estado final de los cambios previstos del V.T.O, la primera superposición es del punto basión a nasión en el punto CC, brindándonos la primera área de evaluación, dentro de la que valoramos la cantidad de crecimiento del mentón en milímetros. El mentón crece a lo largo del eje facial en conjunto con el primer molar superior. El eje facial rota abriéndose o cerrándose por efectos de la aparatología aplicada. La segunda superposición se encuentra dada por el punto basión,- nasión en nasión y muestra cualquier cambio en el maxilar superior. Brindándonos la segunda área de evaluación que permite evaluar la profundidad del maxilar. El ángulo basión-nasiónpunto A no cambia en el crecimiento normal. La acción de la aparatología en tipo y fuerza, produce cambios en el ángulo mencionado

La tercera zona de superposición se refiere al eje del cuerpo en PM, en el desarrollo normal se mantiene constante el con el plano de la dentición. Contribuyendo a la tercera y cuarta área de evaluación, presentada a nivel de las piezas dentarias inferiores, permite definir si se va a intruir, extruir, adelantar o retruir los incisivos inferiores, para determinar el tipo de arco a emplear. A nivel de la cuarta zona de superposición se encuentra dada a nivel del paladar en ENA establece

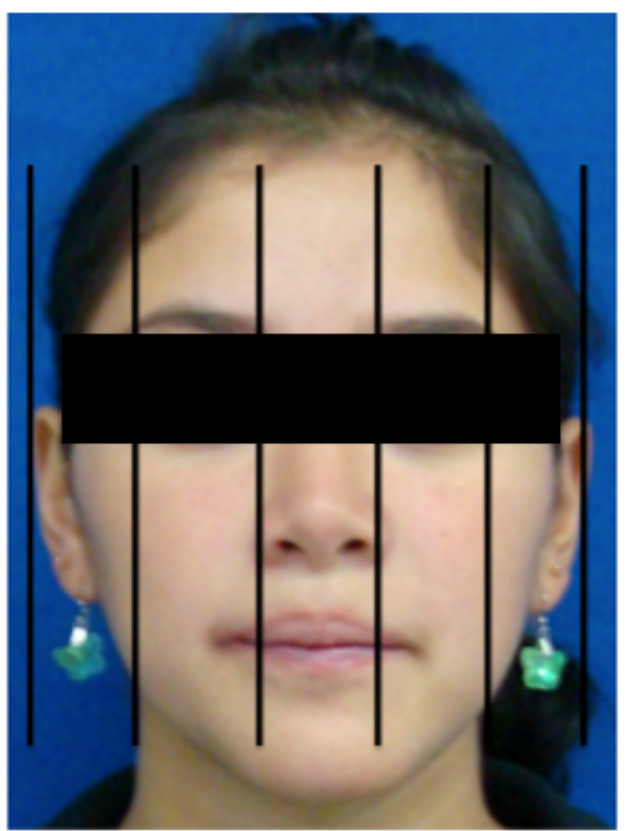

Fig. 6. Análisis de quintos faciales.

los cambios que se puedan presentar en maxilar superior. El crecimiento de molares e incisivos superiores crecen sobre el eje polar. Brinda las áreas cinco y seis de evaluación, valorando los cambios que se produzcan en piezas dentarias de maxilar superior. La quinta zona de superposición es dada por el plano estético en la intersección del plano oclusal, brindándonos el perfil de tejidos blandos, y crea la séptima área de evaluación referente a tejido blando. Existen dos prototipos de V.T.O. tomando como referencia el crecimiento y desarrollo del paciente siendo el V.T.O. mediato en pacientes con crecimiento y V.T.O. inmediato se realiza en pacientes que ya no están en proceso de crecimiento El V.T.O. se basa en el análisis Cefalómetrico de Ric- ketts, registrando once factores de las estructuras faciales y esqueletales básicas a partir del trazado construcción del objetivo visual de tratamiento.

El índice facial se analiza mediante una línea vertical que pase por nasion hasta gnation y una línea horizontal que pase por el zygion bilateralmente (Figura 10); se obtiene como el porcentaje entre la medida vertical y horizontal facial multiplicada por 100 , con un porcentaje menor en la estética contemporánea femenina $86.2 \%$ y en un $88.5 \%$ en la masculina. ${ }^{5}$ Se encuentra reportado además el índice facial de Bruges el cual se basa en una línea descrita por Da Vinci en su análisis de proporciones faciales en la cual trazaba una línea horizontal a la altura más superior al reborde supraorbitario (marcado como la porción màs alta de la ceja clínica) así como una línea interpupilar comparada contra el plano sagital facial. ${ }^{10}$ Ambos análisis nos permiten evaluar la relación 


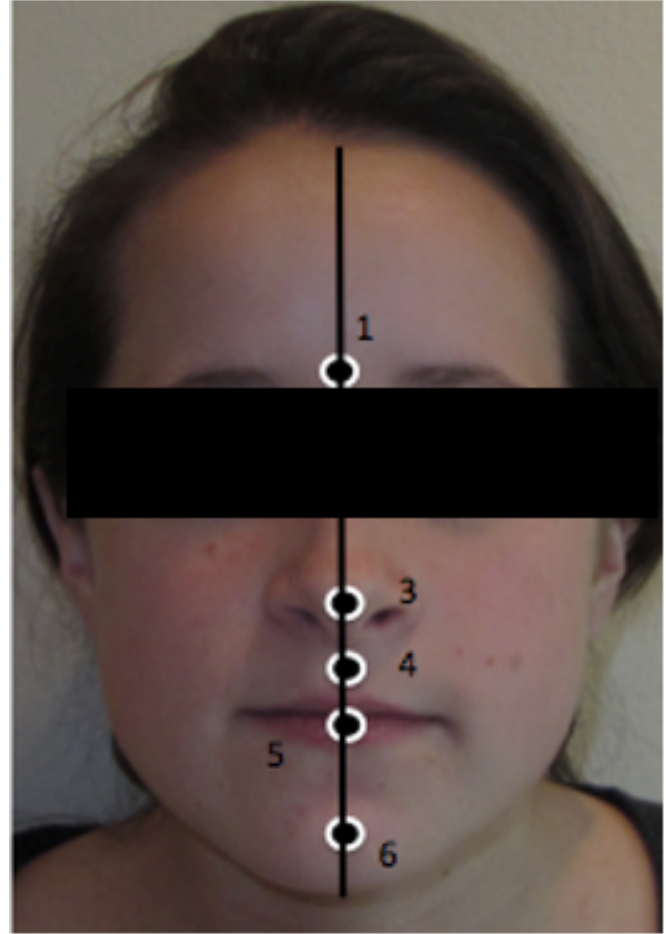

Fig. 7. Evaluación de simetría facial. (1) Glabela, (2) dorso nasal, (3) punta nasal, (4) porción media de filtrum, (5) línea media dental, (6) sínfisis mentoniana.

de ancho y alto facial representando a primera instancia el aspecto facial armónico.

\section{DISCUSIÓN Y CONCLUSIONES}

El análisis estético dento facial constituye la base para el diagnóstico y elaboración de planes de tratamiento que abordan de forma integral los problemas dento esqueletales de pacientes con patología deformante, síndromes cráneo faciales, pacientes con labio paladar hendido y sus secuelas, mala posición de los maxilares, deformidades pos traumáticas entre otras. Este análisis permite recuperar la fisiología cráneo facial sin dejar de lado la recuperación estética, que en una visión holística es la manera indicada de resolver este tipo de patologías ya que no podemos deslindar la fisiología con la percepción estética del individuo ya que el rostro es la contextualización física de la auto percepción del paciente y a su vez es como se lo identifica en el entorno social en que se desempeña. Debemos analizar los patrones de estética desde una perspectiva antropológica, cultural, social, de género y por rangos de edad, el análisis que hemos realizado dá la pauta académica para iniciarse en el estudio de la estética facial. Existen dos vías para realizar el análisis dento facial para el análisis de la cara las que hemos descrito, siendo la clínica la más importante. La evaluación por medios de imagen y digitales del objetivo de visual de

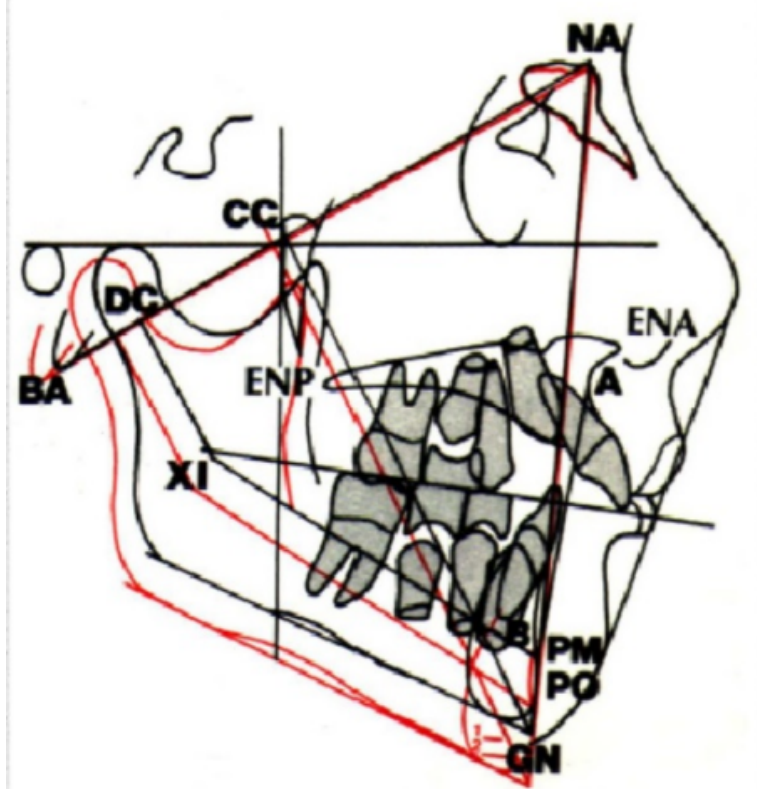

Fig. 8. Superposición de puntos cefalométricos en estructuras anatómicas.

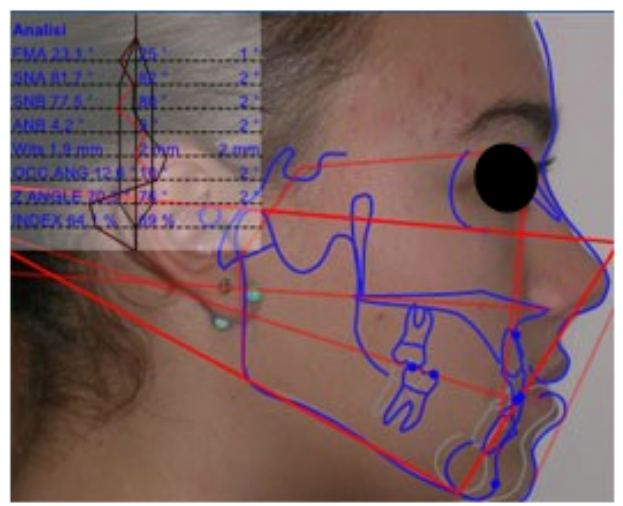

Fig. 9. Proyección digital a la clínica.

tratamiento se constituyen como una herramienta básica para corroborar los hallazgos clínicos y a su vez nos permite ejecutar planes de tratamiento virtuales para buscar la mejor manera de resolver los problemas de los pacientes.

Conflicto de intereses y financiamiento Los autores declaran no tener conflicto de intereses, haber cumplido con los requisitos de autoría y haber autofinanciado este artículo.

\section{Referencias}

1 Howe TN. Vitruvius: the ten books on architecture. London: Cambridge University Press; 1999. 


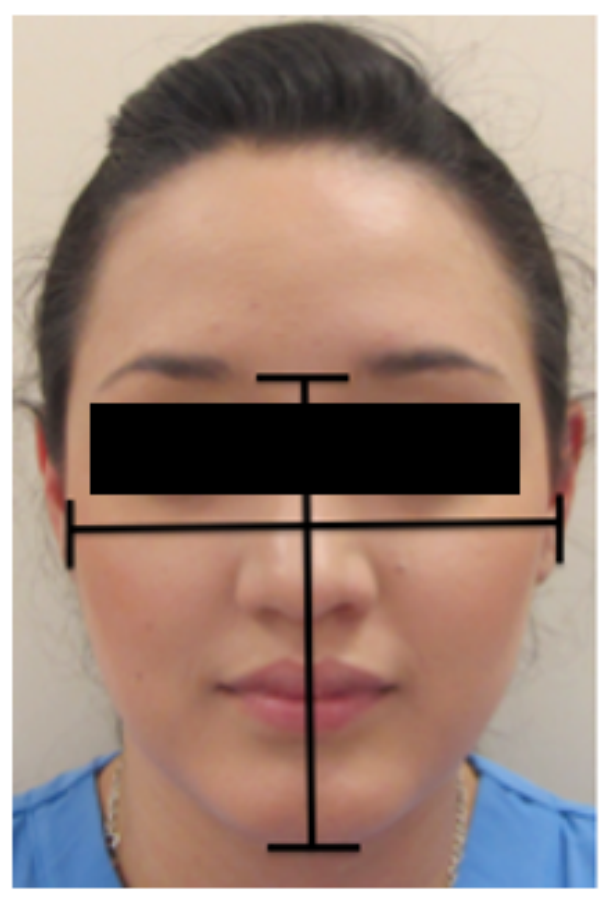

Recibido: 16 de enero de 2017.

Aceptado: 20 de marzo de 2017.

Fig. 10. Índice facial clásico.

2 Farhad B. Naini, James P. Moss and Daljit S. Gil. The enigma of facial beauty: Esthetics, proportions, deformity and controversy Am J Orthod Dentofacial Orthop 2006;130:277-82.

3 Arnett Willian G. Gunson Michael and Richard P. McLaughln. Distraction Osteogenesis of the Facial Skeleton. William H. Bell, Cèsar Guerrero. BC Deker Inc.

4 Arnett GW, Jelic JS Kim J et al. Soft tissue cephalometric analysis: diagnosis and treatment planning of facial deformity. Am J Orthod Dentofacial Orthop 1999;116:239-53 .

5 David Sarver, Ronald S. Jacobson. The Aesthethic Dentofacial Analysis. Clin Plastic Surg 342007 369-394

6 Johan P. Reyneke Essencials of Orthognatic Surgery.. Quintessence Publishing.

7 Navarro Villa. Tratado de Cirugìa Oral y Maxilofacial.

8 Larry M. Wolford, Frank W Hillard, Daniel J. Dugan. Surgical Treatment Objective. A sistematic approach to the prediction traicing.

9 Mommaerts M.Y.,Moherenhunt B.A.M.M.L.Ideal proportions in full face front view, contemporary versus Antique. Journal of Cranio-Maxillo-Facial Surgery 392011 $107 \mathrm{e} 110$

10 Mommaerts M.Y.,Moherenhunt B.A.M.M.L. Reliability of clinical measurements used in the determination of facial índices. Journal of Cranio-Maxillofacial Surgery 2008 36, $279 \mathrm{e} 284$. 
